$\underline{\text { Reports }}$

\title{
An assessment of Bangabandhu Sheikh Mujib Medical University for improving the research capacity
}

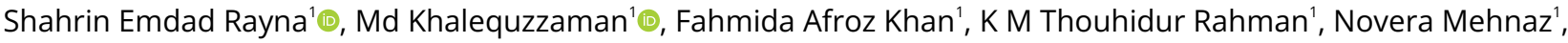 \\ Nusrat Jahan', Ferdous Hakim², M Mostafa Zaman², Syed Shariful Islam \\ ${ }^{1}$ Department of Public Health and Informatics, Bangabandhu Sheikh Mujib Medical University, Shahbag, Dhaka, Bangladesh, 2 Research and \\ Publication, World Health Organization, Bangladesh Office, Dhaka, Bangladesh \\ Keywords: bangladesh, medical education, research capacity, publications output \\ https://doi.org/10.29392/001c.26315
}

Journal of Global Health Reports

Vol. 5, 2021

\section{Background}

Bangabandhu Sheikh Mujib Medical University (BSMMU) is a postgraduate medical university in Bangladesh, where health research is an institutional mission. To improve the institutional research culture that contributes to better research capabilities, an assessment of BSMMU's research output, challenges faced while conducting research, feasible actions to overcome them, and indicators for evaluating the research capacity were identified.

\section{Methods}

Published manuscripts from BSMMU for the year 2018, registered with PubMed and BanglaJOL, were reviewed to assess the status of research output. Key informant interviews and in-depth interviews were conducted with various members of the academic departments, central library, institutional review board and University journals, to identify research-related challenges, strategies to overcome, and indicators to evaluate the research capacity.

\section{Results}

In 2018, the total number of scientific articles published was 364, among which $68.4 \%$ of the articles were published in local journals and $31.6 \%$ in international journals. Journals published by the University lacked indexation into international medical databases and had no impact factor. The majority of the interviewees mentioned about the lack of dedicated time for research, prioritized research agendas and need for research-related trainings to improve research performance as challenges. Establishing policies for research support, development of University's research infrastructure and better mechanisms to disseminate research findings, were identified as key opportunities for improvement. For future evaluation of research capacity strengthening, individual levels indicators (publication outputs, research grants, awards, number of collaborations) were emphasized.

\section{Conclusions}

Preference for publishing in the local journals was observed rather than in international peer-reviewed journals. The key challenges for undertaking research included the absence of dedicated time and trainings for skill development. Publication outputs, research grants, awards, number of collaborations were identified as notable indicators for evaluating improvements in research capacity at an individual level. Establishing policies and guidelines for research support, along with the development of appropriate research infrastructure in the University, will enable it to guide national policies and programs.

Health research has been acknowledged to play a vital role in progress towards the Sustainable Development Goals. ${ }^{1}$ It is known to guide health systems, develop new initiatives and generate evidence-based health policies. ${ }^{2}$
However, there remain gaps in the production of health research, particularly in many low and middle-income countries (LMICs). This can be overcome by developing robust research institutions with skilled researchers and by gener- 
ating evidence to build their own health policies in order to achieve their health-related goals. ${ }^{3}$ This is an era of evidence-based medicine, which has been known to contribute significantly to the practice and advancement of medical science. ${ }^{4}$ Evidence suggests that patients who receive care in research-active hospitals have better health outcomes, as their problems are identified sooner, there is greater availability of more comprehensive treatment options and opportunities to be included in clinical trials. ${ }^{5}$ The Harris Interactive Survey, 2011, revealed that $75 \%$ of the public were eager to participate in clinical trials if the opportunity arose. $^{6}$ Thus, generating research-oriented medical workforces is necessary. ${ }^{7}$

The development of the research capacity of an institute is primarily based on developing the individual research skills and boosting the research culture of institutions, which ultimately leads to an improvement in the research capacity and research excellence at the national level. ${ }^{8}$ Early introduction to scientific research and engagement in research work is known to enhance knowledge on research and develop practical skills. This is not only limited to protocol submission, manuscript writing skills, and methodological and data analysis skills, ${ }^{9}$ but also some soft skills like leadership and management skills. These enable the development for critical appraising, troubleshooting, idea generation, etc., among the researchers. As a result, it encourages involvement in research activities, generates scientific publications, and ultimately supports entry to varying research-focused careers. ${ }^{7}$ Equivalently, developing and promoting the research culture of health care institutions is imperative to encourage research and increase the research output. Research culture is reflected through the faculty member's beliefs and norms about research in the universities, which should provide a conducive research environment. But universities in developing countries have retained strong teaching functions and weak research functions, ${ }^{10}$ indicated by low research output.

Bangladesh has low visibility of its research outputs in the global research community, ${ }^{11}$ and was ranked as the country with the least number of scientific publications among the Southeast Asian countries included in Scopus. ${ }^{12}$ As a result, many quality published works have a limited readership in the country, and low citations from colleagues contribute to the poor visibility and low impact factors. ${ }^{13}$ Data from Web of Science and Scopus revealed that Bangladesh published most in the fields of Medicine, but a very limited number of health care institutes contribute to it. ${ }^{12}$ This reflects the small number of health researchers in the country and decades of underinvestment in research institutions. ${ }^{14}$ Therefore, there is a critical need to develop research capacity in health care settings like medical universities and their hospitals, to inform service planning and decision-making in health services.

Among the many health care institutions in Bangladesh, Bangabandhu Sheikh Mujib Medical University (BSMMU) is a postgraduate medical university that provides specialized patient care by being active in training, education and research. The health professionals of this institute constitute a crucial talent that needs to be continually supported for undertaking research for their prosperity in the research arena. In light of this reality, there is a need to improve the University's research capacity and develop a strong research orientation among health professionals. Hence, an initiative was taken by the Department of Public Health and Informatics (DPHI), BSMMU, in collaboration with the World Health Organization (WHO) - Bangladesh office, to evaluate the situation of the research conducted by the University. This will be corroborated by identifying the potential barriers for undertaking research, strategies to overcome them and decide indicators for systematically tracking the trends and progress of research in the future. This study will be a first of its kind done in any health care institution of Bangladesh with the hope of shaping research culture among the health service providers of this country.

\section{METHODS}

An assessment was conducted to appraise the University's research output, address the gaps and challenges for conducting research, identifying feasible actions for improvement, and determination of indicators for future evaluation of the University's research capacity. Data collection was performed from August to October 2019, by reviewing the scientific publications done from BSMMU for the duration of January to December 2018, and interviews with various staff members of the University.

\section{ASSESSMENT OF THE SCIENTIFIC PUBLICATIONS FROM BSMMU}

A review of the scientific publications from the academic departments to assess the research output from the University was conducted. We utilized PubMed ${ }^{15}$ and Bangladesh Online Journals (BanglaJOL) ${ }^{16}$ databases to select the articles. All the articles published from January 01 to December 31, 2018, were included in this analysis. The particular keywords used for searching articles were "Bangabandhu Sheikh Mujib Medical University” or "BSMMU”, and any article having an author affiliated with BSMMU was taken into account. The screening language was limited to English. The data were compiled onto Microsoft Office Excel-2010 spreadsheets and analyzed. Descriptive analyses were performed on the publications data to generate frequencies and percentages.

\section{INTERVIEWS TO IDENTIFY CHALLENGES, FEASIBLE ACTIONS TO OVERCOME THEM AND INDICATORS FOR EVALUATION OF RESEARCH CAPACITY STRENGTHENING}

To accomplish a comprehensive assessment of the University's research support systems to provide academic, administrative and financial services for research activities, the list of research management and support systems (RMSS) components generated by Wallis et al., 2017, ${ }^{14}$ was utilized. The primary data collection tool developed was a guideline of semi-structured questions for interviews with members of different faculties of the University. Ten indepth interviews with professors and associate professors who were vested in research, and two key-informant inter- 
views with an assistant librarian and a member of the institutional review board, were done to identify the challenges for undertaking research, possible strategies to overcome the afore-mentioned challenges in research support systems, and determination of indicators for future evaluation of the research capacity of the University. The authors themselves conducted the interviews for this study, as they had past experience in conducting in-depth interviews. They were able to develop rapport and trust with the participants very easily, as they were medical doctors themselves. Every interview was audio-recorded with the consent of the participant, along with notes taken by the research assistant. After every interview, extensive discussions with the authors and research assistants were held to compare notes and discuss findings and meanings where necessary to minimize any possibilities for misinterpretation of the participant narratives. All the interviews conducted were translated into English for analysis by the authors themselves. Data were analyzed manually by applying the thematic framework analysis method. To ensure the reliability of data interpretations, the final categories and their contents were conferred among all the authors.

\section{ETHICS CONSIDERATIONS}

This study was considered to be an assessment of an institution aimed to improve and strengthen its research capacity. Therefore, formal ethical approval was not sought. However, verbal consent was taken from every study participant after explaining the objectives of the study, and provided them with an opportunity to withdraw their participation without any consequences.

\section{RESULTS}

\section{RESEARCH PUBLICATIONS}

A review of the publications revealed a total of 364 articles of which, 115 (31.6\%) were found in PubMed and 249 (68.4\%) in BanglaJOL, for the year 2018. Among those in PubMed, majority (69.8\%) were original research articles followed by $16.2 \%$ case reports, $10.0 \%$ review papers, $4.0 \%$ others (two systematic reviews and one letter to the editors, and comment each). A large portion (32.7\%) of the articles were published in Mymensingh Medical Journal, which is indexed and included in Index Medicus and MEDLINE. ${ }^{17}$ A total of 36 departments from the University contributed to the articles in PubMed. As shown in Figure 1, majority (19) of the articles were published from the department of Psychiatry, among which 14 of the articles were published in the Asian Journal of Psychiatry (not shown in the figure). The second highest number of articles (8) was published from the departments of Rheumatology and Internal Medicine, which was followed by Endocrinology (7), and 6 articles each from the departments of Hepatology, Public Health \& Informatics, and Obstetrics \& Gynaecology.

For the articles found in BanglaJOL (249), 67.7\% were original research articles, $23.6 \%$ case reports, $5.6 \%$ review papers and $2.1 \%$ editorials. The preferred journal for publication was the Bangabandhu Sheikh Mujib Medical Univer-

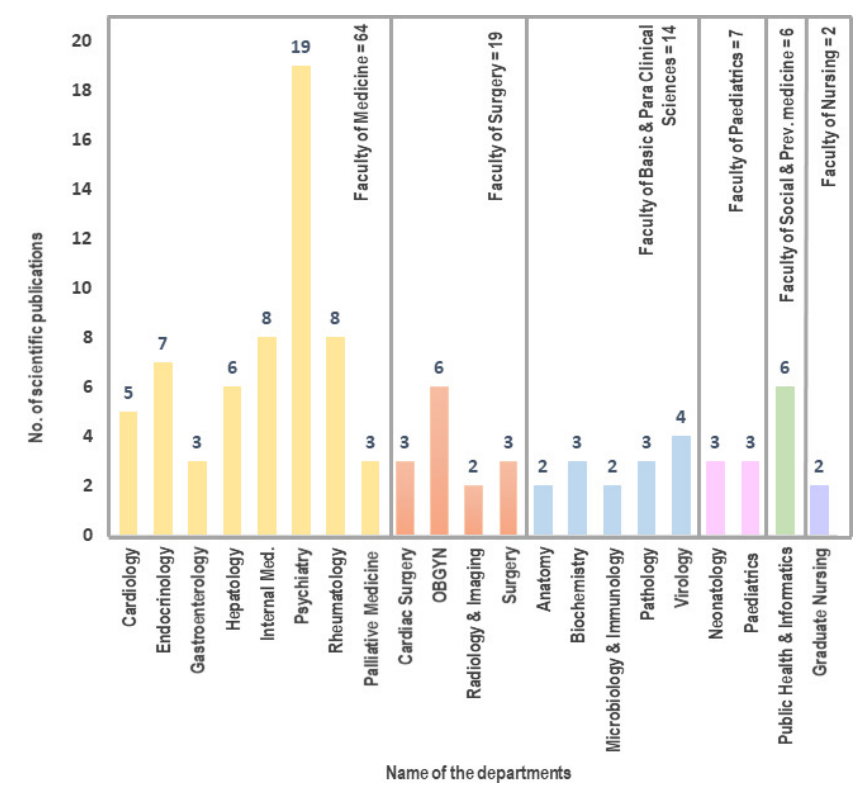

Figure 1. Number of scientific publications listed in PubMed by the departments of BSMMU in 2018

Note: Departments with publications $\leqslant 1$ are not included in the graph

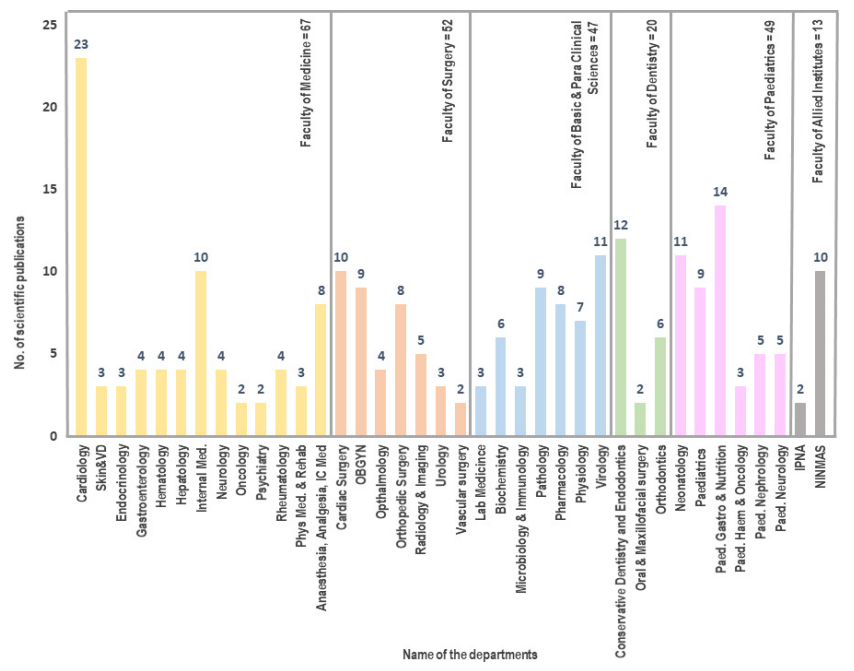

Figure 2. Number of scientific publications listed in BanglaJOL by the departments of BSMMU in 2018

Note: Departments with publications $\leqslant 1$ are not included in the graph

sity Journal (25.8\%) and University Heart Journal (11.7\%), both being published by BSMMU. As illustrated in Figure 2 , the highest number of articles published was from the department of Cardiology, which contributed to 23 articles and Cardiac Surgery contributed to 10. The department of Paediatric Gastroenterology \& Nutrition had the second highest number of publications (14) and the departments of Conservative Dentistry and Endodontics ranked third (12).

The research productivity of the faculty members was expressed in Table 1, where the publication output per faculty member for the year 2018 was calculated. Based on the publication rate, the top performing faculty was the Faculty of Preventive and Social Medicine (1.167). When all the faculties and their employees were combined, the publication/ 
Table 1. Publication per faculty member in 2018

\begin{tabular}{lcccc}
\hline \multicolumn{1}{c}{ Faculty } & $\begin{array}{c}\text { No. of } \\
\text { departments }\end{array}$ & $\begin{array}{c}\text { No. of faculty } \\
\text { members }\end{array}$ & $\begin{array}{c}\text { No. of } \\
\text { publications }\end{array}$ & $\begin{array}{c}\text { Publication/ } \\
\text { faculty } \\
\text { member }\end{array}$ \\
\hline $\begin{array}{l}\text { Preventive and Social Medicine } \\
\text { Basics and Para-clinical }\end{array}$ & 1 & 6 & 7 & 1.167 \\
Sciences & 8 & 54 & 61 & 1.130 \\
Pediatrics & 8 & 58 & 57 & 0.983 \\
Medicine & 16 & 152 & 131 & 0.862 \\
Dentistry & 5 & 29 & 21 & 0.724 \\
Surgery & 17 & 179 & 2 & 0.397 \\
Nursing & 1 & 12 & 350 & 0.167 \\
Total (by Faculty) & 56 & 490 & 14 & 0.714 \\
Allied Institute & 3 & 30 & 364 & 0.467 \\
Total (All) & 59 & 520 & 0.700 \\
\hline
\end{tabular}

faculty member rate was 0.714 , which further decreased to 0.70 when the allied institutes were added to the faculties.

\section{CHALLENGES AND OPPORTUNITIES IDENTIFIED FOR RESEARCH CAPACITY STRENGTHENING}

Respondents sharing their views revealed multiple challenges and constructive ways for strengthening the research support systems of the University. The results are categorized according to the relevant list of items generated by the research management support system described elsewhere. ${ }^{14}$ The findings from the interviews are enumerated in Table 2 .

\section{INDICATORS FOR FUTURE EVALUATION OF RESEARCH STATUS}

For the future assessment of improvement in the research capacity of the University, the most common indicators mentioned by the interviewees are presented in Table 3 . The indicators are categorized according to the level at which they are targeted: individual, institutional and societal. ${ }^{18}$

\section{DISCUSSION}

This study demonstrated a concise process for the assessment of the research activities conducted from BSMMU, the identification of potential gaps and feasible strategies to improve the University's research capacity and indicators for the future evaluation of University's research capacity. The year 2018 was considered for the evaluation. The study revealed a diverse assortment of health research done in the University, of which $68.4 \%$ published manuscripts were found in local journals. The top local journals preferred for publication were Mymensingh Medical Journal, BSMMU Journal, and University Heart Journal, the latter two being published by BSMMU. Some possible reasons for choosing local journals for publications might be because, it is a lowbarrier way to publication, easy formatting style for man- uscript preparation, short duration from submission to acceptance which expedites promotion in academia, and the effort to fulfil the criteria for the journal's indexation into international databases. A wide variability of the publication rates among the faculties was observed ranging from 1.167 to 0.167 . The average publication rate of the faculty members of BSMMU was 0.70, which was comparatively low to other medical institutes, such as, the average publication rate of the American University of Beirut faculty members was $1.24,{ }^{19}$ and in the University of Nebraska College of Medicine it was $1.95 .^{20}$ Such low publication rates can be possibly be attributed to heavy clinical workload, lack of protected time for research, the size of faculty, absence of mentors, etc. According to a report by Scientific Bangladesh, BSMMU was not a leading contributor of health research from Bangladesh in the Scopus database. ${ }^{21}$ This observation is supportive to our findings, where the total number of scientific publications from BSMMU was small in number and majority of them were in the local journals. Publishing in local journals is favorable in many cases, since it encourages the researchers to address agendas pertaining to their country, whereas publication in international journals steer researchers away from local agendas toward topics of international concern. ${ }^{22}$

The study was able to identify multiple challenges for conducting research in the University. Among them, the most commonly mentioned was the burden of excessive clinical and academic workload, which left minimal time allotted for research. This lack of protected time for research, along with the deficiency of institutionalized training programs for the skill development of health care professionals, created apprehension towards research. Adding to this apprehensiveness, is the inadequate infrastructure of the University and lack of support services creating an unfavorable environment for research. Hence, among many faculties, research has become an individual activity conducted within the margins of their departments, rather than utilizing institutional processes. ${ }^{23}$ The challenges found in the current study resonates with the institutes based in LMICs, where they mentioned; heavy teaching loads, weak organi- 
Table 2. Consolidated identified gaps in research management and support systems and suggested actions from the interviews, by RMSS components

\begin{tabular}{|c|c|}
\hline Gaps & Suggested actions \\
\hline \multicolumn{2}{|l|}{ Research strategies and policies } \\
\hline $\begin{array}{l}\text { - No research policy or strategy available } \\
\text { for the institute }\end{array}$ & $\begin{array}{l}\text { - Develop an attainable research policy or strategy that can be utilized by departments and act } \\
\text { as a guidance for the management of research. }\end{array}$ \\
\hline $\begin{array}{l}\text { - Absence of plans for prioritizing research } \\
\text { topics in each department }\end{array}$ & $\begin{array}{l}\text { - University needs to plan for and prioritize the health needs of the population of the country, } \\
\text { where research for a specified period on a particular topic will generate evidence from our } \\
\text { country's perspective. }\end{array}$ \\
\hline $\begin{array}{l}\text { - Unclear guidelines for research protocol } \\
\text { reviews and none available for the various } \\
\text { members of IRB, detailing their roles and } \\
\text { responsibilities }\end{array}$ & $\begin{array}{l}\text { Establish regulations and policies for ethical reviews of research proposals, along with guide- } \\
\text { lines for the IRB members for maintaining professional standards of conduct and prevent in- } \\
\text { fringement of those. }\end{array}$ \\
\hline $\begin{array}{l}\text { - Lack of authorship guidelines promoted } \\
\text { by the University }\end{array}$ & $\begin{array}{l}\text { - Departments need a meticulous authorship guideline to support the contributing authors, and } \\
\text { to avoid authorship malpractice. }\end{array}$ \\
\hline \multicolumn{2}{|c|}{ Institutional support services and infrastructure } \\
\hline $\begin{array}{l}\text { - Lack of research support offices and/or } \\
\text { inadequate coordination among depart- } \\
\text { ments for collaborative research }\end{array}$ & $\begin{array}{l}\text { - Proactive engagement between the research members from various departments needs to be } \\
\text { encouraged. } \\
\text { - Collaborate with other contract research organizations to overcome the lack of in-house re- } \\
\text { search facilities. }\end{array}$ \\
\hline $\begin{array}{l}\text { - Insufficient development of research in- } \\
\text { frastructure within the University to sup- } \\
\text { port research }\end{array}$ & $\begin{array}{l}\text { - Urgent upgradation and integration of information and communication technology (ICT) facili- } \\
\text { ties for storing and monitoring patient's history, diagnostic report, and track the current health } \\
\text { condition, which can be used for research. } \\
\text { - Establish dedicated research laboratory facilities with international accreditation. } \\
\text { - } \text { Covelop clear processes and diminished costing for researchers wishing to access lab facilities. } \\
\text { - } \text { for future research. } \\
\text { Improved access to health science journals in the library by increasing subscriptions of Elsevier } \\
\text { tranet and appropriate listing of all scientific and academic outputs from all departments of } \\
\text { BSMMU. }\end{array}$ \\
\hline $\begin{array}{l}\text { - Inadequate inclusion of research related } \\
\text { activities in the post graduate curriculum }\end{array}$ & $\begin{array}{l}\text { - Revision and emphasis of research-based courses in the postgraduate curriculum. } \\
\text { - Early planning for thesis's proposal development and writing to reduce hassles and delays re- } \\
\text { lated to submission. } \\
\text { - Include publication of original thesis findings in University's journals/international peer-re- } \\
\text { - Dedicated day for poster presentation of all the resident student's thesis ensuing their defense } \\
\text { examinations. }\end{array}$ \\
\hline $\begin{array}{l}\text { - Inefficient tracking and cataloging of re- } \\
\text { search proposals with corrections and } \\
\text { amendments }\end{array}$ & $\begin{array}{l}\text { - Establishment of electronic management system for cataloguing all the proposals with their re- } \\
\text { view decisions and corrections. } \\
\text { - Development of a checklist to be attached with every proposal undergoing review process list- } \\
\text { ing the changes/ corrections made with written notifications on decisions regarding approval/ } \\
\text { disapproval of proposal. }\end{array}$ \\
\hline \multicolumn{2}{|l|}{ Human resource management for research } \\
\hline $\begin{array}{l}\text { - Academic and administrative workloads } \\
\text { overburdening the researchers } \\
\text { - Lack of appreciation for the researchers } \\
\text { in the University } \\
\text { - Very few doctoral students in the Univer- } \\
\text { sity } \\
\text { - No formal postdoctoral career posts for } \\
\text { researchers and non-existent career } \\
\text { paths for research staff }\end{array}$ & $\begin{array}{l}\text { - Dedicated time slots for research related activities assigned by the University's authority. } \\
\text { - Motivate researchers by enticing them with yearly recognition or awards, waivers for publica- } \\
\text { stract/ poster presentation. } \\
\text { - Formal doctoral and post-doctoral programs need to be established to develop skilled re- } \\
\text { - } \text { searchers in health care. }\end{array}$ \\
\hline \multicolumn{2}{|l|}{ Human resource development for research } \\
\hline $\begin{array}{l}\text { - Deficiency in continued professional de- } \\
\text { velopment of resident students/ re- } \\
\text { searchers/library staff/IRB staff }\end{array}$ & $\begin{array}{l}\text { - Early introduction into research skills training for resident students. } \\
\text { - Training needs assessment for all research staff will enable in developing tailored training pro- } \\
\text { grams. }\end{array}$ \\
\hline
\end{tabular}




\begin{tabular}{|c|c|}
\hline Gaps & Suggested actions \\
\hline & $\begin{array}{l}\text { - Establish institutional programs, for technical improvement of resident students which mainly } \\
\text { include statistical knowledge and use of statistical software, research articles writing skills, etc. } \\
\text { - For research staff more attention should be given for developing non-technical skills such as } \\
\text { project management, leadership, supervision \& monitoring, etc. } \\
\text { - IRB committee members need both initial and continuing education and training in research } \\
\text { ethics, methodology and governance. } \\
\text { - Periodic trainings of the library staff to retain their knowledge of computer skills, literature } \\
\text { search, database management, etc. }\end{array}$ \\
\hline \multicolumn{2}{|l|}{ External promotion of research } \\
\hline $\begin{array}{l}\text { Promotion of the research activities and } \\
\text { successes are not publicized well enough }\end{array}$ & $\begin{array}{l}\text { - Regular emendation of the University's website to include all current research activities and } \\
\text { publications. } \\
\text { - Ensure easy accessibility to University's website along with proper functional hyperlinks. }\end{array}$ \\
\hline \multicolumn{2}{|l|}{ National research engagement } \\
\hline $\begin{array}{l}\text { - Very few research outputs from the insti- } \\
\text { tution have the ability to influence na- } \\
\text { tional policies }\end{array}$ & $\begin{array}{l}\text { - University should publicize its research findings more on the national forums for its uptake into } \\
\text { the national policies and programs. } \\
\text { - Improvement into the researcher's capability to write medical jargon free press releases. }\end{array}$ \\
\hline
\end{tabular}

Table 3. Indicators for evaluation of improving research capacity

\begin{tabular}{|c|c|c|}
\hline Level & Component & Evaluation indicators \\
\hline \multirow[t]{3}{*}{ Individual } & - Publications & $\begin{array}{l}\text { Publication output: publication quantity (number of articles), quality (journal impact } \\
\text { factor), and impact (citations, webpage visits). }\end{array}$ \\
\hline & $\begin{array}{l}\text { - Recognition of research } \\
\text { leadership }\end{array}$ & Awards received, invitations as speaker/plenary member \\
\hline & - Career trajectory & $\begin{array}{l}\text { Number of research projects engaged in, number of grants for new projects } \\
\text { received, number of new collaborations. }\end{array}$ \\
\hline \multirow[t]{3}{*}{ Institutional } & - Trainings & Trainings: numbers, participation rates \\
\hline & $\begin{array}{l}\text { - Establishing research } \\
\text { environment }\end{array}$ & $\begin{array}{l}\text { Availability of research related strategies and policies (e.g.: Finance, IRB, Human } \\
\text { Resources) }\end{array}$ \\
\hline & & $\begin{array}{l}\text { Improved ICT facilities in the University, dedicated research laboratories and their } \\
\text { accreditation, developing a biobank, open access to Elsevier and Springer journals, } \\
\text { indexation of University's journals in international medical indexes. }\end{array}$ \\
\hline Societal & $\begin{array}{l}\text { - Research impact and } \\
\text { user engagement }\end{array}$ & $\begin{array}{l}\text { Community impact of research and research influenced policies: number of } \\
\text { dissemination/workshops/ press releases/ policy briefs. }\end{array}$ \\
\hline
\end{tabular}

zational research systems, limited access to scientific information, slow internet connections and inadequate physical facilities including libraries and laboratories as the major disincentives. ${ }^{14,23}$ Along with the challenges, we also identified many options which can be addressed by BSMMU to improve the individual and organizational capacity for research. In order to strengthen research capacity at individual level, early induction of the clinicians into research, and continued tailored training programs are needed. The importance of fostering basic research skills (proposal writing, statistical analysis, article writing skills, etc.), along with soft skills (communication, leadership, research management, etc.) had been highlighted by many interviewees. Seamless integration of these trainings as a part of the post-graduate curriculum is also expected to ensure sustainable changes at the individual capacity, also recommended by Bateman et al. ${ }^{24}$ Likewise, incentives like awards for research, grants with travel and training components, financial support for publication into high-impact journals, formalized career tracks for research staff, are well recognized schemes to inspire the researchers. Such strategies to strengthen research skills have often been recommended in other studies. ${ }^{14,25,26}$ Some approaches for strengthening institutional capacity includes; establishing research support offices, developing inter-departmental collaborations, prioritizing research agendas, developing research management capacity, support from contract research organizations, and upgradation of the University's facilities (ICT and labs) to exclusively support research. To execute the afore mentioned issues, commitment from the management is vital to achieve changes in policies, rules and systems, which will support research. But focusing on strengthening research capacity at institutional level is a challenging task fraught with complexities, where it is not only about changing processes, but also about addressing power structures, politics, relationships and incentives. ${ }^{25}$ Even though this study was able to identify challenges faced for conducting research at both individual and insti- 
tutional level, it failed to bring forth the challenges faced at the national level, where initiatives to apprise and enhance the capacities of government bodies, academic institutions and private sectors for demanding and utilizing research needs to be boosted. This will not only lead to developing an enabling environment for research but also contribute to the social and economic development of the nation.

For tracking the progress of research in the University, multiple indicators were mentioned in this study, where much emphasis was given on publication outputs (especially in high impact journals), followed by the assessment of the researcher's leadership recognition and career trajectory. Publication outputs were acknowledged as the most commonly accepted measures of research capacity building and have been cited previously in many studies. ${ }^{24,26-28}$ But some have argued that using research publication in high impact journals as an indicator, is a tall order for faculties in institutes having low research skills, neither does it address issues to do with the usefulness of research, the impact of research activity on practice, or on measuring health improvement. ${ }^{29}$ Very few of the interviewees mentioned about the importance of institutional indicators (e.g., availability of research related trainings, improvement in various aspects of research infrastructure, etc.) and societal indicators (e.g., assessing the community impact of research, development of research influenced policies, etc.). The limitations of individual indictors in presenting a holistic view of the improvement of research capacity, can be overcome by utilizing the institutional and societal indicators for assessing research infrastructure and impact.

Our current study methods can be utilized by other institution for evaluating and optimizing their research capacity, however some limitations need to be considered. The study was done to provide a broad overview of BSMMU's research status and capacity, which limited the capacity of the study to explore many components in depth. The study participants were purposively selected, who were invested in research and generally revealed similar problems. Also, conducting the study in only one University limited the generalizability of the results, which has been interpreted cautiously due to the lack of any standard comparison. Although the publications review from our end revealed many important observations, we were unable to perform some sophisticated analysis to address the publication capacity of the faculty members with regards to their rank, age, gender, etc. The review was also inadequate to reveal the international collaborations of the publications, as a major bulk of the articles in the local journals did not have all their authors' institutional affiliations listed. Lastly, more variables such as impact factors, citation index, conference presentations, research grants were not considered in this study due to the unreliability and incompleteness of the data received from various departments.

\section{CONCLUSIONS}

This study is a first of its kind, conducted in Bangladesh, where the assessment of the research outputs from an institution and approaches to build on its research capacity was investigated. Although publications in international peer reviewed journals are visible, it is still under the dominance of local journals. The journals published from the University needs nourishment to achieve the standard of the international indexing authorities to attract more manuscripts from within and outside of the country. The key challenges identified for the health care professionals in the field of research included the absence for dedicated time to undertake research and the lack of research related skill developing trainings. The importance of embedding research culture among the health professionals, with establishing policies and guidelines for research support, along with the development of appropriate research infrastructure, will enable BSMMU to cater to the need for future generations to guide national policies and programs.

\section{ACKNOWLEDGEMENTS}

The authors would like to thank the University staff members who participated in the study. We are grateful to the all the departments of the University and especially to the members of the DPHI, BSMMU, for providing valuable support during the research work. We would also like to acknowledge the technical support received from the study and administration team from WHO for their support in this study.

\section{FUNDING}

The study received financial support from World Health Organization, Reference number 2019/919408-0, Project number SEBAN1813696.

\section{AUTHORSHIP CONTRIBUTIONS}

SER contributed in literature review, study design, data collection, analysis and interpretation, manuscript writing and revisions. MK contributed to study design, data analysis and interpretation, and manuscript revisions. FAK, KMTR, $\mathrm{NM}, \mathrm{NJ}$ and FH contributed in literature review, data collection and analysis, and manuscript revisions. MMZ and SSI contributed to data interpretation and finalization of the manuscript. All authors have read and approved the final manuscript.

\section{COMPETING INTERESTS}

The authors completed the Unified Competing Interest form at www.icmje.org/disclosure-of-interest/ (available upon request from the corresponding author) and declare no conflicts of interest.

\section{CORRESPONDENCE TO:}

Dr Md Khalequzzaman, M.B.B.S., M.P.H., M.Sc., Ph.D.

Department of Public Health and Informatics

Room \# 309, Block \# B

Bangabandhu Sheikh Mujib Medical University, Shahbag, Dhaka 1000, Bangladesh 


\section{REFERENCES}

1. Health in 2015: From MDGs, Millennium Development Goals to SDGs, Sustainable Development Goals. World Health Organization; 2015. Accessed January 15, 2021. https://www.who.int/publications/i/ item/9789241565110

2. Health Research: Essential Link to Equity in Development. Oxford University Press, USA; 1990. Accessed December 12, 2020. http://www.cohred.org/ publications/open-archive/1990-commission-report/

3. Koon AD, Nambiar D, Rao KD. Embedding of Research into Decision-Making Processes. Alliance HPSR, WHO, Geneva, Switzerland; 2012:27.

4. Sheridan DJ, Julian DG. Achievements and Limitations of Evidence-Based Medicine. Journal of the American College of Cardiology. 2016;68(2):204-213. doi:10.1016/j.jacc.2016.03.600

5. Young E. The importance of research in healthcare. South Sudan Medical Journal. 2015;8(4):90-91.

6. The Need for Awareness of Clinical Research. National Institutes of Health (NIH). Published May 28, 2015. Accessed April 12, 2021. https://www.nih.go v/health-information/nih-clinical-research-trials-yo $\underline{\mathrm{u} / \text { need-awareness-clinical-research }}$

7. Abu-Zaid A. Research skills: the neglected competency in tomorrow's 21st-century doctors. Perspect Med Educ. 2014;3(1):63-65. doi:10.1007/s400 37-013-0087-7

8. Glencross MJ, Mji A. The role of a research resource centre in the training of social science researchers. South African Journal of Higher Education. 2001;15(2):179-185. doi:10.10520/EJC36818

9. Meerah TSM, Osman K, Zakaria E, et al. Measuring graduate students research skills. Procedia-Social and Behavioral Sciences. 2012;60:626-629.

10. Sanyal BC, Varghese NV. Research capacity of the higher education sector in developing countries. Presented at: UNESCO Forum on Higher Education, Research and Knowledge; November 29, 2006; Paris.

11. Hossain Shoeb Z. Developing an institutional repository at a private university in Bangladesh. OCLC Systems \& Services: International digital library perspectives. 2010;26(3):198-213. doi:10.1108/106507 $\underline{51011073634}$
12. Mahbuba D, Rousseau R. Scientific research in the Indian subcontinent: selected trends and indicators 1973-2007 comparing Bangladesh, Pakistan and Sri Lanka with India, the local giant. Scientometrics. 2010;84(2):403-420. doi:10.1007/s11192-010-0203-y

13. Islam M, Akter R. Institutional Repositories and Open Access Initiatives in Bangladesh: A New Paradigm of Scholarly Communication. LIBER Quarterly. 2013;23(1):3-24. doi:10.18352/lq.8245

14. Wallis S, Cole DC, Gaye O, et al. Qualitative study to develop processes and tools for the assessment and tracking of African institutions' capacity for operational health research. BMJ Open. 2017;7(9):e016660. doi:10.1136/bmjopen-2017-01666 $\underline{0}$

15. PubMed Overview. PubMed. Accessed February 19, 2021. https://pubmed.ncbi.nlm.nih.gov/about/

16. Bangladesh Journal Online. Accessed February 20 2021. https://www.banglajol.info/index.php/index/ab out

17. Mymensingh Medical Journal (MMJ). Accessed February 20, 2021. http://www.mmc.gov.bd/mmi.htm

18. Khisa A, Gitau E, Pulford J, Bates I. A Framework and Indicators to Improve Research Capacity Strengthening Evaluation Practice. Liverpool School of Tropical Medicine Centre for Capacity Research and African Population and Health Research Centre; 2019. doi:10.13140/RG.2.2.27767.37287

19. Dakik HA, Kaidbey H, Sabra R. Research productivity of the medical faculty at the American University of Beirut. Postgrad Med J. 2006;82(969):462-464. doi:10.1136/pgmj.2005.042713

20. Ellwein LB, Khachab M, Waldman RH. Assessing research productivity: evaluating journal publication across academic departments. Academic Medicine. 1989;64(6):319-325.

21. Research collaboration: DU ranks top in Bangladesh. Dhaka Tribune. https://www.dhakatribun e.com/bangladesh/education/2020/01/09/research-col laboration-du-ranks-top-in-bangladesh. Published January 9, 2020. Accessed February 3, 2021.

22. Leach M, Waldman L. Centres of Excellence? Questions of Capacity for Innovation, Sustainability, Development. STEPS Centre; 2009. Accessed March 18, 2021. https://opendocs.ids.ac.uk/opendocs/handl $\mathrm{e} / 20.500 .12413 / 2452$ 
23. Harle J. Foundations for the Future: Supporting the Early Careers of African Researchers: A Paper Commissioned by the British Academy as Part of the Nairobi Process. British Academy; 2011.

24. Bateman H, Walter F, Elliott J. What happens next?: Evaluation of a scheme to support primary care practitioners with a fledgling interest in research. Family Practice. 2004;21(1):83-86. doi:10.10 93/fampra/cmh118

25. Vogel I. Research Capacity Strengthening Learning from Experience.; :49. Accessed December 15, 2020. ht tps://www.ukcdr.org.uk/wp-content/uploads/2018/03/ UKCDS_Capacity_Building_Report_July_2012.pdf

26. Cooke J. A framework to evaluate research capacity building in health care. BMC Fam Pract. 2005;6(1):44. doi:10.1186/1471-2296-6-44
27. Lee M, Saunders K. Oak trees from acorns? An evaluation of local bursaries in primary care. Primary Health Care Research \& Development. 2004;5(2):93-95. doi:10.1191/1463423604pc197xx

28. Lester HE, Carter YH, Dassu D, Hobbs FD. Survey of research activity, training needs, departmental support, and career intentions of junior academic general practitioners. Br J Gen Pract. 1998;48(431):1322-1326.

29. Campbell SM, Roland MO, Bentley E, et al. Research capacity in UK primary care. British Journal of General Practice. 1999;49(449):967-970. 